\title{
Surgery of Nasolabial Cyst: Current Trends vs. Common Sense
}

\author{
Dunja Milicic* \\ Department of Otorhinolaryngology, Hospital da Luz Arrabida, Porto, Portugal
}

Submission: December 17, 2017; Published: December 21, 2017

*Corresponding author: Dunja Milicic, Hospital da Luz Arrábida, Department of Otorhinolaryngology, Praceta de Henrique Moreira 150, 4400346 Vila Nova de Gaia, Portugal, Tel: +351 22377 6800; Email: dmilicic@hospitaldaarrabida.pt

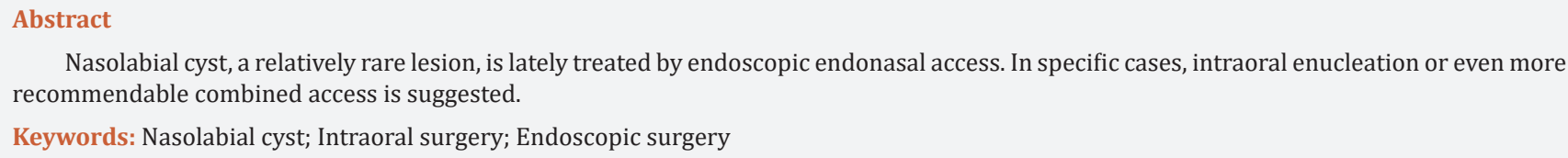

Nasolabial cyst, a relatively rare lesion, is lately treated by endoscopic endonasal access. In specific cases, intraoral enucleation or even more recommendable combined access is suggested.

Keywords: Nasolabial cyst; Intraoral surgery; Endoscopic surgery

\section{Introduction}

A nasolabial cyst, a relatively rare entity of developmental origin, more frequent in middle aged women, is a benign lesion localized in the nasal alar region, in general without endonasal manifestations [1,2]. An intraoral surgical approach, as Denker, even though provides a lager access to the lesion, with visualization of the limits and sensitive structures, it is lately put aside [3]. All complications and pitfalls from this type of surgery are widely known, resulting in a traumatic memory of the surgery by the patients [3]. Lately, there is an urge to resolve everything by endoscopical approach [4,5]. Elegant visualization of all structures with high magnification is very attractive for surgeons and the actual absence of external complications or signs from the surgery makes it very appealing to the patients [6].
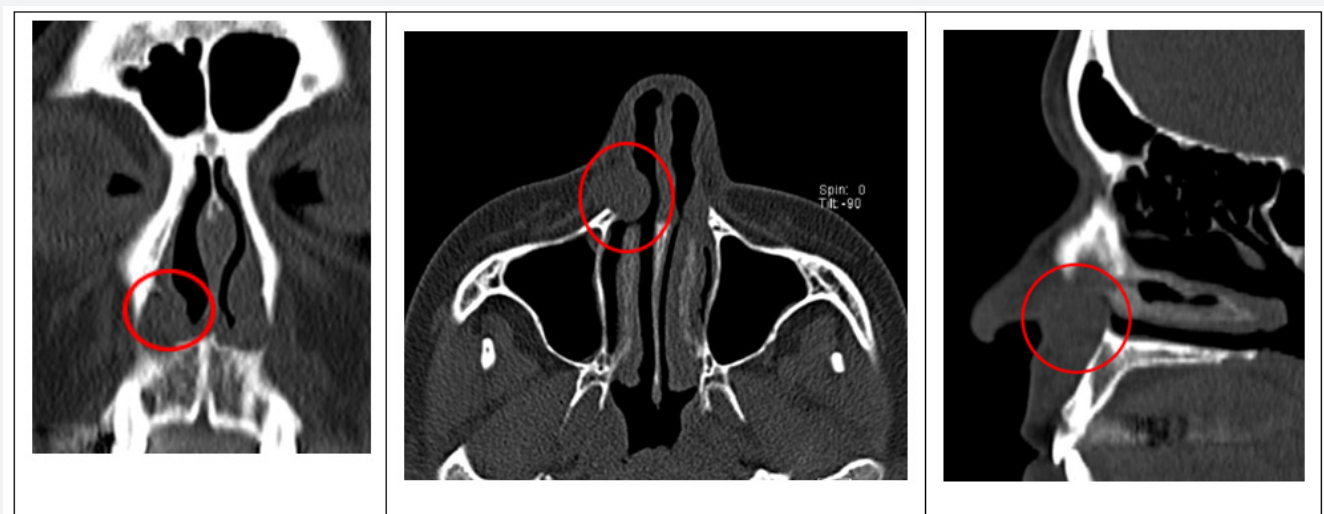

Figure 1: Patient I.M.C.A.P. female, 42 years old, CT scan images of nodular tumor in the right nasolabial region.

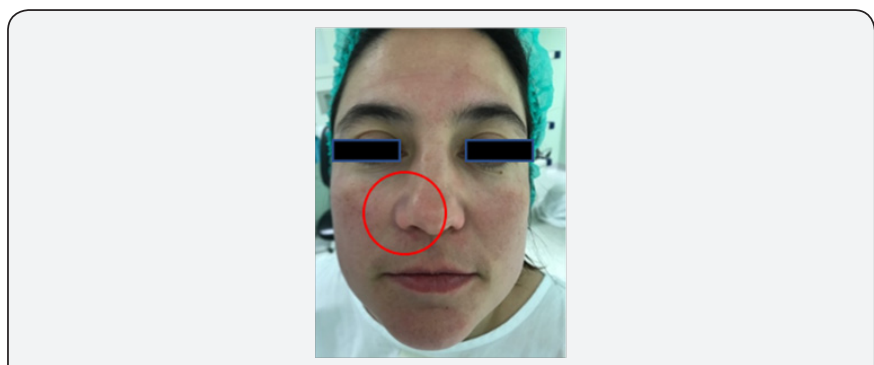

Figure 2: Patient I.M.C.A.P. female, 42 years old, on the day of surgery, with the hardly visible lump in the right nasolabial fold.

\section{Results}

I.M.C.A.P. female, 42 years old, ASA1, noticed a lump on the right nasal ala with right nasal obstruction. The lump, hardly noticeable on the face, was visible under the inferior turbinate by endoscopy and confirmed by CT scan (Figures $1 \& 2$ ). On the day of surgery, approximately 2 months after first observation, the patient referred a pressure on the right side of the nasal pyramid and under the right eye. A surgery, after written informed consent, was performed by combined approach: intraoral and endoscopic access. A typical Denker incision (exposure of nasal sidewall) was performed with 
enucleation of the cyst externally. The monitoring of nasal mucosa was performed by the aid of endoscopy (there was no tearing of nasal mucosa intraoperatively) (Figure 3). The extension of the cyst was $2 \times 2,4 \mathrm{~cm}$, corresponding to the area referred by the patient (a sensation of pressure) with the following limits:

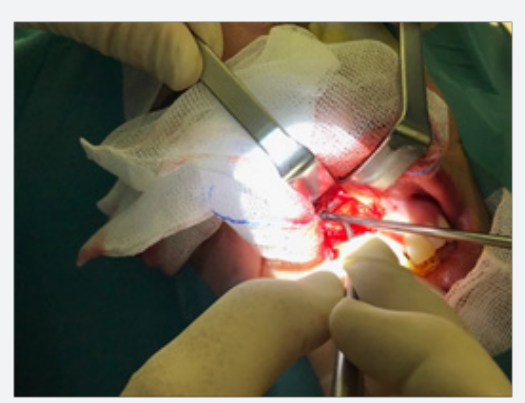

Figure 3: Patient I.M.C.A.P. female, 42 years old, a surgical image of enucleation of the cystic tumor through the Denker's incision on the right side.

a. Anteriorly: wall of maxilla, out of the limits of the sinus cavity.

b. Medially: confirmed erosion of the lateral wall of pyriform aperture in extension of $1 \mathrm{~cm}$.

c. Cranially: at the border of the right orbit.

d. Laterally: at the orifice of the right infraorbital nerve (ramification of trigeminal nerve).

During immediate postoperative course, there was no swelling or hematoma, neither pain nor alteration of the sensibility of the face or teeth. The Pathological Anatomy confirmed a cyst structure lined with pseudostratified columnar epithelium, with complete extraction (in toto).

\section{Discussion}

Lately, an endoscopic approach is used whenever possible, but a critical attitude is necessary versus a real utility of the approach in specific cases [7]. A surgical procedure should not be elected due to its attractiveness or ease in performing it. The importance should be given to techniques that give a definitive resolution of the problem/ disease, as well as improving patient's comfort [8]. Endoscopic surgery could provide all of this $[9,10]$. It is extremely easy in the right hands [10]. But it obliges to have adequate training and equipment, what can be a problem in low and mediumincome countries [11]. In this specific case, the opening of the cyst by an endoscopic approach would make an orifice with large communication between the nasal and cyst cavity. The extension of the cavity would make it difficult to monitor and control. The crusting, retention of pathological secretions (inflammatory healing secretions or pathological nasal secretions), could lead to a variety of complications as well as possible fistulation. Debriding and toilette of a cavity becomes almost impossible. The use of a curved microdebrider is obligatory to remove pathological tissue, which could be a problem in profound cysts, especially with cranial projections. Preservation of the cyst epithelium would lead to recurrence of the lesion and failure of the surgery.

For the patient, all of this translates in discomfort and failure in the resolution of the problem. The first positive patient's reaction, of "easy" and quick resolution surgery can be substituted by angry and understandable in satisfaction. Nowadays, an intraoral approach has negative connotations such as obsolete, "old fashioned", "bloody", traumatic, nor recommendable in simple words. Every surgical technique has its disadvantages. The cost-benefit judgment is sometimes tricky. In this specific case, a combination of traditional surgery with endoscopic endonasal monitoring of mucosa was applied. The extraction was done by a large approach which secured the complete evacuation of the cyst and complete visibility of the lesion's extent, without any of the complications mentioned in the literature. Nasal endoscopy provided an accurate monitoring of the status of nasal mucosa and prevented possible endonasal damage. It was not used as the principal surgical method due to the extension of the lesion, namely cranial progression and to avoid eventual fistulation.

\section{Conclusion}

A critical attitude towards the choice of a surgical technique is essential. Sometimes, a traditional old procedure can still give a better solution then an up-today and recommendable procedure. The importance of endoscopy is not questioned, but in some cases, it could be just an adjuvant component of the surgery, providing a different point of view and therefore promoting security of the surgical procedure. In process of ENT surgery learning, the familiarization with the traditional techniques is mandatory, not only with procedures which are a current trend in surgery.

\section{Conflict of interest}

I confirm there is no financial or personal relationship with any people or organization related to this report/opinion that could inappropriately influence this work.

\section{Acknowledgment}

I would like thank Carolina Serodio, MD, ENT specialist Hospital da Luz Clínica do Porto, Portugal for the help provided during surgery.

\section{References}

1. Roed-Petersen B (1969) Nasolabial cysts: a presentation of five patients with a review of the literature. British Journal of Oral Surgery 7(2): 84-95.

2. Kuriloff DB (1987) The nasolabial cyst-nasal hamartoma. Otolaryngology- Head and Neck Surgery 96(3): 268-272.

3. Sakai SI, Mori N, Miyaguchi M, Itoh M (1991) Combined therapy for maxillary sinus carcinoma with special reference to extensive Denker's operation. Auris Nasus Larynx. 18(4): 367-375.

4. Kennedy DW, Zinreich SJ, Rosenbaum AE, Johns ME (1985) Functional endoscopic sinus surgery: theory and diagnostic evaluation. Archives of Otolaryngology 111(9): 576-582. 
5. Su CY, Chien CY, Hwang CF (1999) A new transnasal approach to endoscopic marsupialization of the nasolabial cyst. The Laryngoscope 109(7): 1116-1118.

6. Wormald PJ (2007) Endoscopic sinus surgery. Thieme.

7. Wreesmann V B, Fokkens WJ, Knegt PP (2001) Refractory chronic sinusitis: evaluation of symptom improvement after Denker's procedure. Otolaryngology-Head and Neck Surgery 125(5): 495-500.

8. Videler WJ, Wreesmann VB, van der Meulen FW, Knegt PP, Fokkens WJ
(2006) Repetitive endoscopic sinus surgery failure: a role for radical surgery?. Otolaryngology-Head and Neck Surgery 134(4): 586-591.

9. Wormald PJ (2007) Endoscopic sinus surgery. Thieme.

10. Kennedy DW, Zinreich SJ, Rosenbaum AE, Johns ME (1985) Functional endoscopic sinus surgery: theory and diagnostic evaluation. Archives of Otolaryngology 111(9): 576-582.

11. Stankiewicz JA (1987) Complications of endoscopic nasal surgery: occurrence and treatment. American Journal of Rhinology 1(1): 45-49.

\section{Your next submission with Juniper Publishers will reach you the below assets}

- Quality Editorial service

- Swift Peer Review

- Reprints availability

- E-prints Service

- Manuscript Podcast for convenient understanding

- Global attainment for your research

- Manuscript accessibility in different formats

( Pdf, E-pub, Full Text, Audio)

- Unceasing customer service

Track the below URL for one-step submission https://juniperpublishers.com/online-submission.php 